\title{
《核技术》投稿要求
}

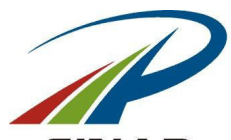

《核技术》创刊于 1978 年, 由中国科学院上海应用物理研究所和中国核学会主办, 旨在展示最新的核科学技术发展动向, 及时反映我国核科学技术的现状和学术水平, 介 绍最新的核科技成果。本刊是北京大学出版社《中文核心期刊要目总览》(第 8 版) 和

SINAP “中国科技论文统计源”收录期刊，被美国化学文摘 $(\mathrm{CA})$ 、日本科学技术文献速报

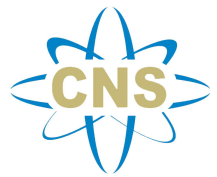
(CBST)、英国 INSPEC 数据库、荷兰 SCOPUS 数据库、中国知网(CNKI)、中国科学引文数据库 $(\mathrm{CSCD})$ 、万方数据库、超星 期刊域出版平台、维普数据库、中国生物医学文献服务系统(SinoMed)、中文生物医学期刊文献数据库(CMCC)和中国生物医 学期刊引文数据库 $(\mathrm{CMCI})$ 收录。本刊的主要学术方向为: 同步辐射技术及应用, 低能加速器技术、射线技术及应用, 核化学、 放射化学、放射性药物和核医学, 核电子学与仪器, 核物理、交叉学科研究, 核能科学与工程等。

1. 稿件形式为综述、研究论文和研究简报。来稿应论点鲜明、数据可靠、结论明确、文字简练。来稿不应载有作者已 公开发表的数据 (会议上口头发表和学位论文除外), 更不可为作者已经 (或想要) 投往他刊的稿件。本刊退稿前, 请勿将 该稿件另投他刊。

2. 请使用以 1986 年 10 月国务院批准公布的《简化字总表》为准的简化字, 数字以国家标准 GB/T15835-2011 “出版物 上数字用法”为准, 计量单位采用国家法定计量单位或许用单位, 参照标准 GB3100-3102-1993。

3. 来稿须用 Word 格式。来稿应反映上述研究领域的最新进展, 篇幅至少为本刊 4 页版面 (约 3000 字数)。图应清晰可 辨，表应简洁明了，置于正文中第一次提及该图表的段落后; 图题、表题及表格中文字均为中英文，图中文字仅为英文。中 英文摘要应包含背景、目的、方法、结果、结论等五要素, 中文摘要宜为 250 字左右。正文的文献引用应按其出现的先后顺 序编号并加方括号上标于正文中, 文末的参考文献应按该编码排列, 中文文献须为中、英文并列表达。所引用的参考文献建 议为 3 年内的, 行业内的经典文献例外。

4. 请登录 www.j.sinap.ac.cn, 点击《核技术》, 进入《核技术》网络投稿平台注册并投稿。请作者妥善保管好登录名和 密码, 以便查询稿件处理状态。

核 技术 (He Jishu)

(月刊 1978 年创刊)

第 43 卷 第 4 期 2020 年 4 月 15 日出版

\section{NUCLEAR TECHNIQUES}

(Monthly Started in 1978)

Vol.43 No.4 April 15, 2020

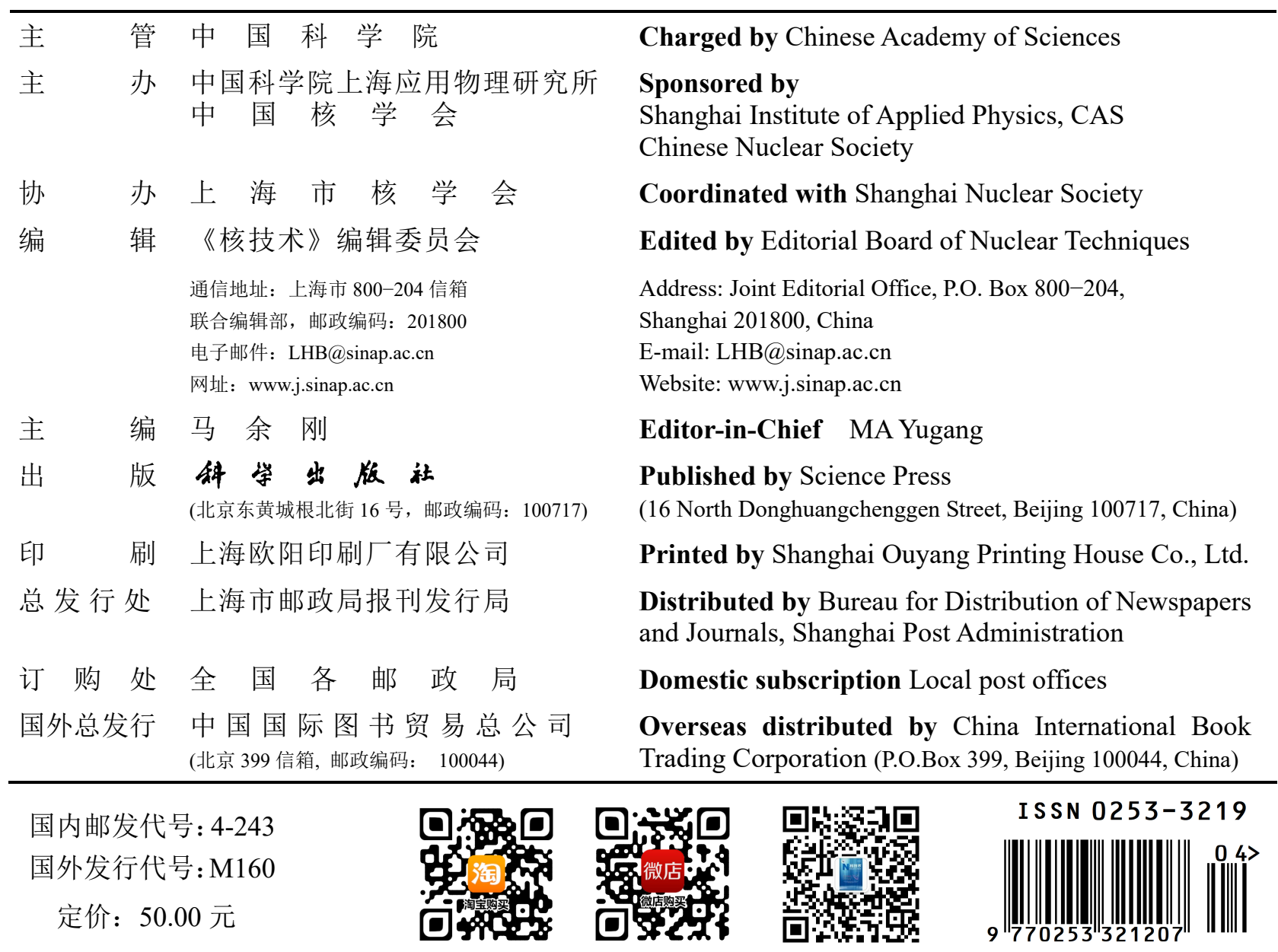

